\title{
Design of Automatic Breeding System for Chickens under the Forest
}

\author{
Wei $\mathrm{Li}^{\mathrm{a}}$, Yuqi $\mathrm{Cao}^{\mathrm{b}}$, Jiahe $\mathrm{Cui}^{\mathrm{c}}$, and Dongming $\mathrm{Li}^{\mathrm{d}^{*}}$ \\ College of Mechanical and Electrical Engineering, Hebei Agricultural University, Baoding, China \\ a869306513@qq.com, b2350353391@qq.com, '1301683942@qq.com, dLdmmail@163.com
}

Keywords: Remote control; Automatic aquaculture system; Undergrowth chicken; Intelligent
monitoring

\begin{abstract}
Breeding chickens in the forest is to use the grass leaves and insect resources in the forest to raise chickens. In order to realize the intelligence of undergrowth chickens, the internet technology has been combined with the model of the undergrowth chicken breeding. The operation of the chicken house has been checked by various sensing devices, and all kinds of real-time information of the chicken house could be learned by the network platform. According to the situation of the chicken house, the automatic control equipments and the intelligent breeding cars in the chicken house have been remotely operated to solve the corresponding problems, so that the chickens could be managed scientifically and automatically, which made the chicken group get the most standardized breeding. Hence the internetwork intervention makes a piece of chicken house in the mountain forest become an organic whole for the rearing staff to facilitate the unified scheduling.
\end{abstract}

\section{Introduction}

In recent years, as people's living standards have improved, the demand for meat and eggs has increased year by year. The chickens raised under the forest are gradually favored by people because of their good quality of chicken, unique taste, and no polluted environment[1]. However, today's traditional forest-raising chicken model lacks intelligent and scientific managing; so many problems have arisen, affecting the quality and yield of chicken and eggs, and greatly reducing economic benefits. In view of the current status of chicken farming technology under the forest, the forest chicken raising technology will be upgraded.

\section{Chicken House Structure and Facilities}

As we all know, the chicken coop was the place where the chickens grew and produced. Whether the environment of the chicken house could meet the suitable production conditions of the flock was related to the health of the flock and the performance of the flock production, thus affecting the quality of the poultry products [2]. According to research, the temperature, humidity and light of the house had a direct impact on the growth, development and egg production of the flock, so the rational design and control of the house environment was very important [3].

Overall framework. The overall structure of the chicken house consisted of an ecological composite board and a foam sandwich insulation board. Lightweight, easy to disassemble, transfer and transport. Gas-filled glass windows were applied to the walls around the house: there were four glass windows on the front wall, taking into account the requirements of the surrounding environment for the chicken during the growing process. The upper two windows could be opened and closed, and the lower two windows were closed. There were four glass windows on the back wall that could be opened and closed. The right wall was openable and glazed, and there was a chicken house entrance. The left wall was openable and glazed, and all the glass windows were covered with iron mesh to prevent the chicken from getting off, as shown in Figure 1. The surrounding walls were connected to each other, having a good sealing, and were fixedly connected by a buckle. There was a chicken house automatic door panel at the entrance of the chicken house. The chicken could be enclosed in the chicken house. The roof of the chicken house was equipped with a windproof rope and fixed on the woodland with ground nails to ensure the stability of the 
chicken house in the bad weather of the forest.

The house had a lockable egg collection device. In order to prevent birds from stealing eggs, a lockable egg collecting device designed was similar to a drawer with a sliding cover. When taking an egg, you could pull the slide directly to remove the egg. Two rows of small pulleys were installed on both sides of the device for easy pulling, saving time and effort.

The base of the chicken house was a 15-degree inclined mesh iron frame. The size of the mesh was moderate, preventing the eggs from falling down, ensuring that the eggs could be smoothly rolled into the egg collecting device, and the chicken droppings were allowed to fall into the chicken manure handling conveyor device below, which was easy to clean.

The whole house could be moved and transferred, and the forest land would be changed in real time, which was conducive to the restoration of woodland vegetation and the cleanup of chicken houses.

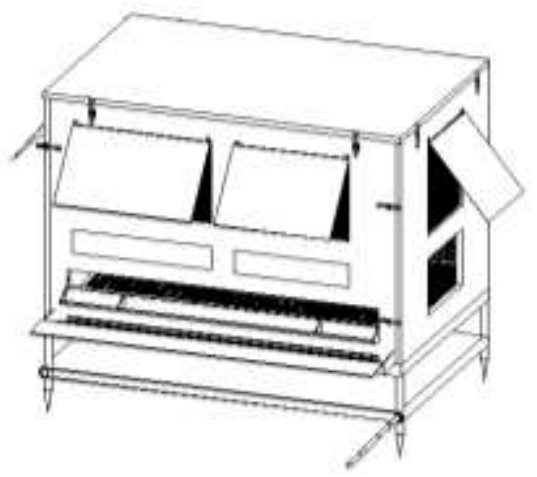

Figure1. Detachable transfer under the chicken house

Ventilation system. The raising-chicken house under the forest was a small chicken house and it was also between the woodlands. Therefore, the normal exchange of gas could be achieved by intelligently controlling the closing of the door and window. The specific technology was to use RF electric swing window sliding arm window opener remote timing intelligent control door and window closure, using mobile phone $\mathrm{Wi}-\mathrm{Fi}, 86$ switch and 100 meters remote control, without stroke control, the maximum can be turned on 90 degrees.

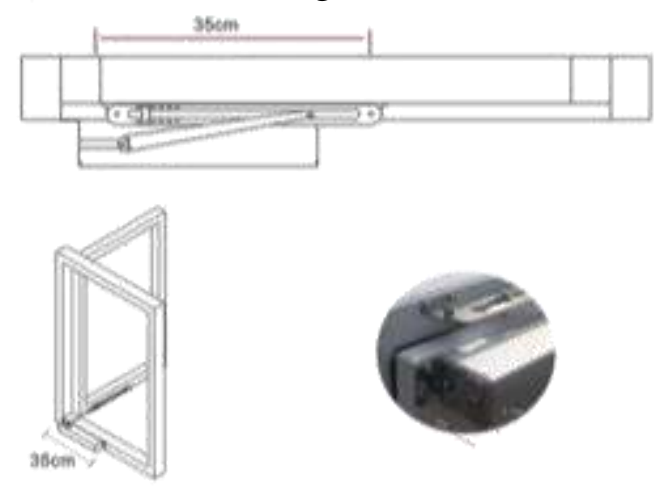

Figure2. Electric swing window sliding arm window opener

Temperature gas control system. The temperature gas control system included temperature, gas concentration and time controllers and electric negative pressure control. According to the standard, the temperature, gas concentration, door and window opening time and negative pressure value were input into the computer, and the circuit was connected with the relevant sensor probe, and the temperature gas concentration controller was used for automatic control, which was displayed by the computer or the mobile phone terminal. The temperature gas concentration time controller was a computer controlled instrument that set the temperature, gas concentration, number of windows and doors open, and time.

Time Control: When the door and window switch time was set, the controller would execute according to the set time. If the setting was 1:30, the door and window would automatically close 
after one and a half hours.

Temperature control: The doors and windows were sequentially opened according to the temperature of the detected house and the temperature set by each grade to ensure the suitability of the temperature control.

Gas control: The sensor device intelligently detected the gas concentration to control the opening and closing of the door and window, and the sensing upper and lower thresholds of the intelligent control binding could be set through the touch screen, and after the sensing value reaches the threshold value, the check control interface could be set by the touch screen. The control operation was fixed, and its control operation could be customized (forward/reverse or on/off), and the air conditioning quality standards of the house were shown in Table 1 [4].

Such as: set the ammonia concentration to $0 \mathrm{ppm}$, first gear $10 \mathrm{ppm}$, second gear 20ppm, third gear 20ppm, fourth gear 20ppm. When the ammonia concentration in the house reached $20 \mathrm{ppm}$, a door and window were opened. When the ammonia concentration in the house fell below $10 \mathrm{ppm}$, the doors and windows were automatically closed. If the ammonia concentration continued to rise above $30 \mathrm{ppm}$, the second door and window would be opened. When the ammonia concentration dropped below 30ppm, the second door and window were closed, and the first door and window were working normally. If the ammonia concentration was still rising, the doors and windows of the later gear would be opened in turn.

Table 1 Chicken house air quality standards

\begin{tabular}{cc}
\hline index & standard \\
\hline oxygen & $\Downarrow 19.6 \%$ \\
carbon dioxide & $《 3000 \mathrm{ppm}$ \\
Carbon monoxide & $《 20 \mathrm{ppm}$ \\
Ammonia & $《 10 \mathrm{ppm}$ \\
Respirable dust & $《 3.4 \mathrm{mg} / \mathrm{m} 3$ \\
Relative humidity & $45-65 \%$
\end{tabular}

Drinking water supply system. There were small towers outside the chicken house, each of which could store about three days of feed to ensure the freshness of the feed. The feed in the tower was filled with the entire trough by the auger rotation, and the injection amount of the feed was detected by the meter to ensure the rationality of the foodstuff. The drinking water system consisted of a water tower, a filter, a water meter, a pressure regulating valve, and a water line. The water line had a nipple drinker, and one nipple was used for drinking water from 10 to 12 chickens. The water meter could detect the change of drinking water of the chicken in real time and upload the terminal.

Lighting system. Solar lights were installed inside and outside the house, which could automatically set the lighting duration to improve the chicken's growth cycle, and also facilitate the observation of the chicken's growth activities, so as to adjust accordingly. Solar incandescent lights equipped in the forest were used to attract insects, increase the abundance of woodland insects, and increase the predation of flocks in the woodland.

Fecal management system. There was an automatic handling of the fecal conveyor belt at the bottom of the house. On the right side of the conveyor belt there was a conveyor shaft, which was driven by the motor to rotate the conveyor belt, so that the manure on the conveyor belt was transported to the manure collection device for easy cleaning. The base of the chicken house was supported by a pointed cone. In view of the fact that it was a soft and rugged woodland, it was supported by a pointed cone and could be deeply inserted into the base layer and fixed on the ground to leave enough space for the installation of the conveyor belt.

Monitoring system. Infrared cameras were installed in the chicken house and around the chicken house to facilitate the real-time monitoring of the activities of the flocks by the farmers. Once an emergency had occurred, it could be solved immediately. Infrared cameras were also installed in places where flocks of woodland often appeared. It was easy to observe the outdoor 
feeding status of the flock and the presence of other beasts in the forest to protect the safety of the flock.

Automatic intelligent breeding vehicle system. The breeding vehicles were mainly used for daily forest patrols, collecting eggs, cleaning up manure, and replenishing water. The car was equipped with surveillance camera equipment, intelligent obstacle avoidance equipment, wireless transmission communication equipment, and remote control tracking system. In addition, an egg collecting device was installed on the vehicle, which could be docked with the egg box, and the eggs in the egg box were collected into the breeding car. There was a water tank and a feed box on the car, which could be fully replenished for the water tower and material tower of the chicken house according to the remaining amount of food. The car was also equipped with an automatic motor that could be seamlessly connected to the shaft of the fecal conveyor belt, which drove the conveyor belt to rotate and the feces on the conveyor belt fell into the feces collection box on the breeding cart.

\section{The Internet Operating System}

Chicken house control system. The Internet cloud platform was used to establish an intelligent management platform for the chicken house information collection and control system, and the intelligent chicken house sensor touch integrated device was used for operation, including integrated industrial touch screen local control, and intelligent control based on real-time sensing parameters linkage ( Support off-line operation), all-weather timing control operation (supporting off-network operation) and remote software watch control operation (pc software, APP, WeChat client). Real-time monitoring and collection using standard model sensor equipment to monitor, regulate and cloud big data storage in the chicken house inner environment and chicken behavior [5]. And through the use of $\mathrm{WiFi}, 4 \mathrm{G}, \mathrm{NB}-\mathrm{IOT}$ and cloud server interconnection, and then achieved data interaction with the host computer software platform, as shown in Figure 3. The breeder observed and detected the condition of the flock every day through the camera and the weight sensor, and recorded in detail the state of feeding, drinking, spirit, and sleeping state of the flock. chickens in special case would be treated timely [6].

In addition, forest land was divided into multiple areas using fishnets or plant hedges [7]. First, sub-regional management was independent of each other, which could prevent the spread of avian diseases [8]. Once a region was found to have poultry diseases, it would immediately isolate the treatment to prevent the expansion of poultry diseases and minimize losses. Second, the breeding areas were delineated to carry out zoning rotation grazing. Even if the chickens get enough natural food, they could effectively protect the forest land resources and make the forest land sustainable use [9].

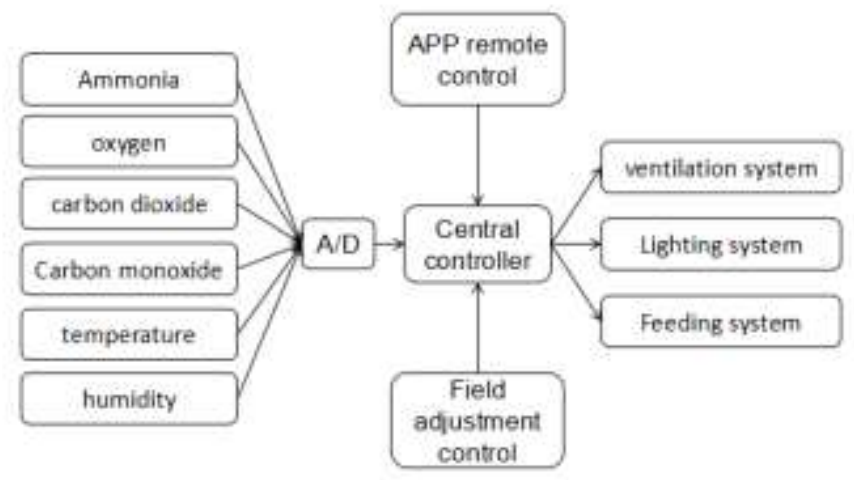

Figure 3. Internet chicken house environment control system

Intelligent farming vehicle system. The crawler type intelligent breeding vehicle adopted a hybrid electric power system, which was inspected 3 times a week to prevent potential threats to chickens in the woods such as rats and beasts, and to prevent the escape of chickens [10]. The inspection began from the breeding base with the feed and water, and worked on all the houses one 
by one following the pre-set route through the woodland. First, according to the remaining amount of food and water in the chicken house that has been uploaded to the cloud, the breeding vehicle would be replenished. Then, the breeding vehicle collected the eggs in the chicken house, and then connected the motor on the breeding car to the rotating shaft of the feces conveyor belt, and drove the conveyor belt to make the feces fall into the feces collecting box on the breeding vehicle. After that, the smart farm car left the house. Along the fixed path to the feces fermentation base and the egg collection base, the manure in the breeding car was unloaded and fermented, and the eggs were collected, sterilized and packaged. Finally, the breeding truck spread the fermented manure into the woodland and used it as a natural fertilizer for forest and grass to accelerate the growth cycle of forest grass [11].

\section{Conclusions}

In view of the demand for green farming in the modern chicken industry, based on the intelligent technology of mountain forest chicken eco-cycle internet, based on the establishment of multi-functional, intelligent and mobile chicken houses, we will study the mobile chicken house facilities suitable for forest establishment. Chicken feeding management equipment such as automated feeding systems, drinking water systems, and manure collection and treatment systems. Establish an intelligent management platform for the information collection and control system of the chicken house to monitor and regulate the internal environment (temperature, humidity, gas, etc.) and chicken characteristics (weight, activity, etc.) in the chicken house [12]. It is intelligent, scientific, and automated, thus saving a lot of manpower and material costs.

\section{Acknowledgements}

This work was supported by the Training Program of Students Innovation and Entrepreneurship in Hebei Agricultural University (201810086014), the Department of Science \& Technology of Hebei Province (16236605D-2), Key Laboratory of Broiler and Chicken Breeding Facilities, Ministry of Agriculture.

\section{References}

[1] Lisanne M. Stadig, T. Bas Rodenburg, Bart Ampe, Bert Reubens and Frank A. M. Tuyttens: Applied Animal Behaviour Science, Vol. 192 (2017) No.7, p.15.

[2] P. Kittisut and N. Pornsuwancharoen: Procedia Engineering, Vol. 32 (2012) p.342

[3] Henry L. Classen: Animal Feed Science and Technology, Vol. 233 (2017) No.11, p.13

[4] J.S. Wang, X.P. Wu and Y.B. Jiang: China National Poultry, Vol. 35 (2013) No.10, p.2.(In Chinese)

[5] Jones T A, Donnelly C A and Stamp Dawkins M: Poultry Science, 2005, 84(8).Vol. 84 (2005) No.8.

[6] Q. Yu: Fujian Agriculture, (2010) No.7, p.26.(In Chinese)

[7] Xin Huo, Pongchan Na-Lampang: Agriculture and Natural Resources, 2016.

[8] Talia Moyle, Kelly Drake, Vaibhav Gole, Kapil Chousalkar and Susan Hazel: Comparative Immunology, Microbiology and Infectious Diseases, Vol. 49, (2016) No.12, p.88.

[9] Tracey Jones, Ruth Feber, Gabriel Hemery and Paul Cook: Agricultural Systems, Vol 94 (2007) No.2, p. 177.

[10] C.W.Xu:Control of Poultry and Poultry Diseases, (2016) No.3, p.38.(In Chinese)

[11] T. S. Mkhabela: Journal of Plant Nutrition, Vol. 29 (2006) No.7, p.12.

[12] R. B. Kjærup, H. R. Juul-Madsen, L. R. Norup, P. Sørensen, and T. S. Dalgaard: Veterinary Immunology and Immunopathology, Vol. 187 (2017) No.5,p.69. 